\title{
Estimação de Probabilidade de Transbordo do Buffer em Redes OFDM-TDMA utilizando Cadeias de Markov e Curva de Serviço
}

\author{
F.H.T. VIEIRA ${ }^{1 *}$, V.H.T. COSTA ${ }^{1}$, L.L. LING $^{2}$ e F.G.C. ROCHA ${ }^{3}$
}

Recebido em 16 março, 2014 / Aceito em 20 fevereiro, 2016

\begin{abstract}
RESUMO. Este trabalho apresenta duas abordagens para estimação de probabilidade de transbordo do buffer em redes OFDM-TDMA. A primeira abordagem, se baseia em Cadeias de Markov e em Teoria de Filas para descrever o desempenho do enlace de transmissão em sistemas OFDM-TDMA. A segunda abordagem se baseia em curva de serviço e no conceito de Processo Envelope. Mais especificamente, foi proposta uma equação para estimação de probabilidade de transbordo do buffer em sistemas OFDMTDMA. Para tal, também deduziu-se uma equação para a curva de serviço de Sistemas OFDM-TDMA. Os resultados obtidos mostram que as estimativas de probabilidade de transbordo baseadas na curva de serviço do sistema se aproximam bem dos resultados da simulação e a complexidade computacional do cálculo necessário para obtê-los é significativamente reduzida em relação ao modelo baseado em Cadeias de Markov.
\end{abstract}

Palavras-chave: Redes OFDM-TDMA, Probabilidade de Transbordo, Cadeias de Markov, Teoria de Filas, Processo Envelope, Curva de Serviço.

\section{INTRODUÇÃO}

Atualmente, a modulação OFDM (Orthogonal Frequency Division Multiplexing [1]) é utilizada em uma gama de redes sem fio de alta velocidade, em redes locais sem fio (WLAN) como o Wi-Fi (padrão IEEE 802.11 [2]), em redes metropolitanas sem fio (WMAN) como o WiMAX (padrão IEEE 802.16 [3]) e no LTE [4]. Todas estas tecnologias são promissoras no mundo contemporâneo das telecomunicações, tendo em vista a inovação trazida e os investimentos recentemente realizados para implantação e desenvolvimento dessas tecnologias em inúmeros países.

Este trabalho apresenta o modelo fundamentado em Teoria de Filas e em Cadeias de Markov descrito em [7] para avaliar o desempenho do enlace de transmissão em sistemas OFDM-TDMA.

\footnotetext{
*Autor correspondente: Flávio Henrique Teles Vieira.

${ }^{1}$ Escola de Engenharia Elétrica, Mecânica e Computação - EMC, Universidade Federal de Goiás - UFG, Goiânia, GO, Brasil. E-mails: flavio@eeec.ufg.br; victor.hugooooo@gmail.com

${ }^{2}$ Faculdade de Engenharia Elétrica e de Computação - FEEC, Universidade Estadual de Campinas - Unicamp, Campinas, SP, Brasil. E-mail: lee@ decom.fee.unicamp.br

${ }^{3}$ Instituto de Informática - INF, Universidade Federal de Goiás - UFG, Goiânia, GO, Brasil.

E-mail: flavio.geraldo@gmail.com
} 
Enquanto a transmissão baseada em OFDM eleva a taxa de transmissão, o acesso por múltiplos usuários é garantido através de TDMA (Time Division Multiple Access) [5]. Do modelo baseado em Cadeia de Markov, são derivados vários indicadores de QoS, como o número médio de pacotes na fila formada para transmissão, o atraso médio na transmissão de um pacote e a probabilidade de a fila de pacotes exceder o tamanho do buffer.

A estimação de probabilidade de transbordo, apesar de apresentar valores precisos, demanda bastante esforço computacional e tempo para se obter uma estimativa. Assim, é proposto nesse artigo um método alternativo baseado em Curva de Serviço para estimação de parâmetros de QoS que apresenta menor complexidade computacional. Em outras palavras, este trabalho apresenta uma equação relativamente simples e bastante eficiente, baseada em Processo Envelope, para estimar a probabilidade de transbordo do buffer do usuário em sistemas OFDM-TDMA.

\subsection{Análise de Desempenho Baseada em Teoria de Filas}

A Teoria de Filas é importante na análise de desempenho de sistemas de transmissão por capturar, em sua essência, a dinâmica do canal de comunicação.

Diferentes trabalhos voltados para a análise de desempenho abordam os sistemas de comunicação sem fio baseados em OFDM em variados aspectos utilizando Teoria de Filas. Chen [10] sugere um modelo para avaliar o desempenho da alocação de subportadoras e derivam expressões para calcular indicadores de probabilidade de bloqueio de chamada e de utilização de banda. Wunder e Zhou [11] propõem limitantes para o tamanho da fila e para o atraso de pacotes no downlink de sistemas OFDM. O modelo desenvolvido é aplicado no dimensionamento de sistemas LTE. Bouchti, Kafhali e Haqiq [12] apresentam um modelo de análise de desempenho de sistemas OFDMA aplicado à tecnologia WiMAX. No entanto, esses trabalhos modelam a chegada de tráfego dos usuários a partir do modelo de Poisson, devido à simplicidade de análise. Porém, é um fato que o tráfego de rede real, em muitas vezes, não segue o comportamento descrito por esse modelo, limitando a utilidade desses trabalhos em situações do mundo real [13] [14].

Neste trabalho, propõe-se estimar a probabilidade de transbordo em redes OFDM-TDMA utilizando modelos fractais [15]. Ou seja, modelos que retratam melhor a característica de dependência de longa duração nos processos de tráfego real, o que torna a solução bastante robusta.

As próximas seções estão organizadas da seguinte forma: a seção 2 estabelece o modelo da transmissão OFDM enquanto a seção 3 descreve o sistema OFDM-TDMA com escalonamento round-robin considerado neste trabalho e define o modelo de análise de desempenho do sistema baseado em Cadeias de Markov; e, por último, a seção 4 define uma equação bastante eficiente e computacionalmente simples para estimação da probabilidade de transbordo do buffer do usuário, apresentando os resultados experimentais e comparando-os com de outros modelos.

\section{TRANSMISSÃO OFDM}

Considera-se que o transmissor possui informações a respeito da qualidade do canal (como a relação sinal-ruído, ou signal-to-noise ratio, SNR) no ato da transmissão de um frame, o que 
possibilita a utilização de modulação e codificação adaptativas. Estas informações podem ser obtidas através do sinal piloto [17].

Mediante o uso de modulação e codificação adaptativas, o número máximo de bits de informação por símbolo amostrado $(\mathrm{Hz})$ que uma subportadora $m$ pode transmitir para um usuário $n$ durante um símbolo OFDM no tempo $t$ pode ser escrito em função da SNR e da probabilidade de erro de bit (Bit Error Rate, BER). Apesar de haver várias aproximações desta função, todas elas são limitadas superiormente pela seguinte expressão do nível de modulação [18]:

$$
c_{m, n}(t)=\left\lfloor\log _{2}\left(1+\frac{-1,5}{\ln \left(5 P_{b e r}\right)} \gamma_{m, n}(t)\right)\right\rfloor
$$

onde $\gamma_{m, n}(t)$ é a SNR instantânea num símbolo OFDM transmitido durante $t$ para uma subportadora $m$ e usuário $n$, e $P_{b e r}$ é a probabilidade de erro de bit.

Seja $C$ o nível de modulação máximo possível. Os níveis de SNR podem ser divididos em $C+1$ intervalos consecutivos e disjuntos com limites definidos como $\Gamma_{c}$, onde $c=0,1, \ldots, C$. Cada região definida equivale a um nível de modulação. Dessa forma, quanto maior a leitura da SNR, maior será o nível de modulação utilizado. Os limites desses intervalos não dependem dos usuários ou das subportadoras pelas quais ocorrerá a transmissão, mas apenas do nível de modulação. Então, a partir da equação 2.1, estes limites podem ser obtidos como:

$$
\Gamma_{c}=\frac{\left(2^{c}-1\right) \ln \left(5 P_{b e r}\right)}{-1,5}
$$

O maior nível de modulação é utilizado desde que a probabilidade de erro de bit se mantenha abaixo do limiar estabelecido. Dessa forma, o nível de modulação $c$ é utilizado quando $\Gamma_{c} \leq$ $\gamma_{m, n} \leq \Gamma_{c+1}$. Quando o nível de modulação é zero $(c=0)$, nenhum pacote é transmitido.

É considerado que a potência de transmissão é fixa e que o canal sofre desvanecimento rápido tipo Rayleigh. A média invariante no tempo da SNR para a subportadora $m$ e usuário $n$ é chamada $\bar{\gamma}_{m, n}$. A SNR recebida, $\gamma_{m, n}$, é, então, uma variável aleatória com a seguinte densidade de probabilidade:

$$
p_{\gamma}\left(\gamma_{m, n}\right)=\frac{1}{\bar{\gamma}_{m, n}} \exp \left(-\frac{\gamma_{m, n}}{\bar{\gamma}_{m, n}}\right)
$$

Assim, a probabilidade de um nível de modulação $c$ ser escolhido para uma subportadora $m$ e usuário $n$ é dada como:

$$
\begin{aligned}
P c_{m, n}(c) & =\int_{\Gamma_{c}}^{\Gamma_{c+1}} p_{\gamma}\left(\gamma_{m, n}\right) \mathrm{d} \gamma_{m, n} \\
& =\exp \left(-\frac{\Gamma_{c}}{\bar{\gamma}_{m, n}}\right)-\exp \left(-\frac{\Gamma_{c+1}}{\bar{\gamma}_{m, n}}\right)
\end{aligned}
$$

Em cada frame transmitido com duração $T$, o número de pacotes $r$ que podem ser transmitidos é definido em função do nível de modulação:

$$
r(c)=\left\lfloor\frac{T \times c \times \Delta f}{L}\right\rfloor
$$


onde $\Delta f=\frac{B}{M}, B$ é a largura de banda do canal de transmissão, $M$ é o número de subportadoras que compõem o canal OFDM e $L$ é o tamanho do pacote transmitido em bits.

Para um usuário $n$, a probabilidade de se utilizar uma determinada taxa de transmissão de pacotes $r_{m}$ numa subportadora $m$ pode ser calculada da seguinte forma:

$$
P r_{m, n}\left(r_{m}\right)=\sum_{r_{m}=r(c)} P c_{m, n}(c)
$$

onde $c=0,1,2, \ldots, C, r_{m}=0,1,2, \ldots, R$ e $R=\left\lfloor\frac{T \times C \times \Delta f}{L}\right\rfloor$.

Para o usuário $n$, a função massa de probabilidade da taxa de transmissão de pacotes durante um frame numa subportadora $m$ é obtida como na equação 2.7 :

$$
r_{m, n}=\left[\begin{array}{llll}
\operatorname{Pr}_{m, n}(0) & \operatorname{Pr}_{m, n}(1) & \cdots & \operatorname{Pr}_{m, n}(R)
\end{array}\right]
$$

Então, a função massa de probabilidade da taxa de transmissão total $\left(\mathbf{R}_{n}\right)$, envolvendo todas as $M$ subportadoras do canal dedicado ao usuário $n$, é dada pela convolução das funções massa de probabilidade das taxas de transmissão de cada subportadora.

$$
\mathbf{R}_{n}=r_{1, n} * r_{2, n} * \ldots * r_{M, n}
$$

\section{MODELO DO SISTEMA OFDM-TDMA}

O cenário envolve a transmissão downlink em um canal baseado na tecnologia OFDM-TDMA para promover acesso a múltiplas estações assinantes. A implementação do múltiplo acesso por divisão de tempo é feita com escalonamento round-robin e todos os usuários são atendidos com períodos de igual duração, assim como feito em [7]. Há $N$ usuários compartilhando um canal com $M$ subportadoras. Cada usuário possui um buffer próprio localizado na estação base com tamanho estabelecido onde o tráfego de entrada é armazenado.

Num ciclo de transmissão, o canal é alocado para cada usuário durante uma janela de tempo para envio de um frame, totalizando, assim, $N$ frames transmitidos ao final do ciclo. A duração de um intervalo de tempo dedicado a um usuário é de $T$ segundos. O número de pacotes transmitidos num frame pode ser diferente dependendo do nível de modulação utilizado em cada subportadora. Pequenos intervalos de tempo são inseridos entre as transmissões de cada usuário com o intuito de evitar interferência.

\subsection{Formulação do Sistema de Filas}

Neste trabalho, considerou-se um modelo analítico baseado em Cadeias de Markov de Tempo Discreto para analisar o desempenho do sistema de fila de um usuário específico que se encontra em estado estacionário. Dessa forma, dadas as funções massa de probabilidade da taxa de transmissão total e do tráfego de chegada, o modelo baseado em Cadeia de Markov pode ser aplicado a qualquer uma das filas. 
O tráfego de entrada de cada usuário é modelado a partir de séries de amostras reais de tráfego de redes IP. A série deve possuir os valores agregados a cada $T$ segundos, a duração da transmissão de um frame. A partir disso, o método MMFM (Markov Modulated Fluid Models) é aplicado e, então, é obtida uma função de densidade de probabilidade $f(v)$ que descreve o processo de chegada de pacotes para cada usuário em estado estacionário. A função de distribuição acumulada, por sua vez, é denominada $F(v)$.

Considera-se, ainda, um número $V$ correspondente ao máximo de pacotes que pode entrar na fila de transmissão durante um frame. A probabilidade de chegar $V$ pacotes é definida como $f(V)=1-F(V-1)$.

O comportamento da fila de pacotes de um usuário pode ser modelado como um processo de quase nascimento e morte [19] e, dado o domínio discreto do tempo, uma matriz de probabilidade de transição da Cadeia de Markov, $\mathbf{P}$ (de elementos $\mathbf{p}_{x, x^{\prime}}$ ), pode ser definida.

A matriz $\mathbf{P}$ é quadrada e suas linhas representam o número de pacotes $(x)$ na fila, enquanto os valores $\mathbf{p}_{x, x^{\prime}}$ representam a probabilidade de transição da fila do estado $x$ para $x^{\prime}$, ou seja, de $x$ pacotes no presente para $x^{\prime}$ pacotes no início da transmissão do próximo frame.

Uma vez definida a matriz de transição $\mathbf{P}$, pode-se estimar as probabilidades do sistema se encontrar em cada estado em regime permanente e, a partir disso, determinar vários parâmetros de qualidade de serviço.

No sistema OFDM-TDMA, o conjunto de estados que a fila de um determinado usuário pode assumir num frame $i$ é definido como:

$$
\Delta=\left\{\left(\mathcal{X}_{i}, \mathcal{N}_{i}\right), 0 \leq \mathcal{X}_{i} \leq X, 1 \leq \mathcal{N}_{i} \leq N\right\}
$$

onde $\mathcal{X}_{i}$ é o número de pacotes encontrados na fila, $X$ é o tamanho do buffer, $\mathcal{N}_{i}$ corresponde ao usuário sendo servido durante o frame e $N$ se refere ao número de usuários no sistema.

Uma vez que os usuários são servidos sequencialmente e de maneira circular, uma matriz de transição $\mathbf{U}$ pode representar o escalonamento round-robin. Esta matriz tem dimensões $N \times N$ e cada linha representa o usuário que está sendo servido no momento. Sendo assim, a linha $n$ representa que o usuário $n$ está sendo atendido pelo sistema no frame atual.

Considerando que $R$ seja a maior taxa de transmissão total e $V$ o número máximo de pacotes que pode entrar na fila de transmissão durante um frame, podemos definir as relações $A=$ $\min (X-x, V)$ e $D=\min (x, R)$. A probabilidade de transição da fila de um usuário do estado $x$ para $x^{\prime}$ depende de qual usuário está sendo atendido e é determinada pela matriz diagonal $\mathbf{V}_{x, x^{\prime}}$, de dimensões $N \times N$ dada por [7].

$$
\left[\mathbf{V}_{x, x^{\prime}}\right]_{i, i}=\left\{\begin{array}{l}
\sum_{v-r=x^{\prime}-x} f(v)\left[\mathbf{R}_{n}\right]_{r+1}, \quad i=n \\
f\left(x^{\prime}-x\right), \quad i \neq n, x^{\prime} \geq x
\end{array}\right.
$$

onde $x-D \leq x^{\prime} \leq x+A, r=0,1, \ldots, R$ e $v=0,1, \ldots, V . \mathbf{R}_{n}$ é o vetor que contém a função massa de probabilidade da taxa de transmissão total para o usuário $n$ (equação 2.8) cuja fila está sendo analisada. $\left[\mathbf{V}_{x, x^{\prime}}\right]_{i, i}$ indica o elemento na linha $i$ e coluna $i$ da matriz diagonal $\mathbf{V}_{x, x^{\prime}}$. 
Os valores $\mathbf{p}_{x, x^{\prime}}$, que formam a matriz de transição do sistema, são calculados segundo a equação 3.3. Observa-se que cada $\mathbf{p}_{x, x^{\prime}}$, neste cenário, é uma matriz de dimensões $N \times N$.

$$
\mathbf{p}_{x, x^{\prime}}=\mathbf{U} \mathbf{V}_{x, x^{\prime}}
$$

Calculando-se todos os valores $\mathbf{p}_{x, x^{\prime}}$, para $0 \leq x \leq X$ e $x-D \leq x^{\prime} \leq x+A$, obtém-se a matriz de transição completa do sistema.

Considerando que os estados da Cadeia de Markov que modela o sistema são recorrentes e aperiódicos, as probabilidades do sistema se encontrar em cada estado são determinadas pelo vetor $\pi=\left[\begin{array}{lllll}\pi_{0} & \pi_{1} & \cdots & \pi_{i} & \cdots\end{array}\right]$ [20]. Este vetor pode ser obtido a partir da matriz de transição da Cadeia de Markov antes definida, por meio da solução do seguinte sistema de equações lineares:

$$
\begin{gathered}
\boldsymbol{\pi}=\boldsymbol{\pi} \mathbf{P} \\
\sum_{i \in S} \pi_{i}=1
\end{gathered}
$$

\subsection{Estimação de Parâmetros de QoS}

Os parâmetros de QoS são calculados a partir das probabilidades em estado estacionário do sistema se encontrar em cada estado possível.

Como, para cada um dos $X$ estados da fila, o modelo considera os $N$ diferentes estados para o escalonamento round-robin, a probabilidade em estado estacionário da fila do usuário considerado conter $x$ pacotes (onde $0 \leq x \leq X$ ) pode ser calculada como:

$$
\pi(x)=\sum_{i=(x \times N)+1}^{(x+1) \times N}[\pi]_{i}
$$

A partir destes valores, pode-se obter o número médio de pacotes na fila (backlog):

$$
b=\sum_{x=0}^{X} x \pi(x)
$$

O atraso médio de um pacote (delay), definido como o tempo médio (em frames) que um pacote espera na fila desde sua chegada até sua transmissão, é dado pela lei de Little [6]:

$$
d=\frac{b}{\lambda}
$$

onde $\lambda$ é o número médio de pacotes que chegam por frame, obtido a partir da média da série de tráfego considerada depois de agregada em intervalos de tempo equivalentes à duração do frame. Uma vez que a fila de pacotes no buffer do usuário passa para o estado $X$ toda vez que ocorre transbordo, $P(X \mid T)=1$. Portanto:

$$
\pi(X)=P(T)+P(X \mid \bar{T}) P(\bar{T})
$$


Podemos aproximar a probabilidade de transbordo do buffer da seguinte forma:

$$
P_{\text {transb }} \approx \pi(X)
$$

Basicamente, todos os passos envolvidos neste método para a obtenção de estimativas dos parâmetros de QoS podem ser resumidos no seguinte algoritmo:

Algoritmo 1. Estimação de Parâmetros de QoS

1. Determinar a função massa de probabilidade da taxa de transmissão total do usuário $n$ ( $\mathbf{R}_{n}$ - equação 2.8);

2. Encontrar, a partir de $\mathbf{R}_{n}$ e $f_{n}(v)$, a matriz de probabilidade de transição de estados da fila do usuário no sistema OFDM-TDMA (P);

3. Calcular as probabilidades, em regime permanente, do fila do usuário se encontrar em cada estado possível ( $\boldsymbol{\pi}$ - equações 3.4 e 3.5);

4. Calcular as estimativas dos parâmetros de QoS (equações 3.7, 3.8 e 3.10).

\section{PROBABILIDADE DE TRANSBORDO BASEADA EM CURVA DE SERVIÇO}

Nesta seção, é proposta uma equação para estimação da probabilidade de transbordo do buffer de um usuário com base no processo envelope do tráfego e na curva de serviço do sistema. A equação definida pode ser utilizada para diferentes sistemas de transmissão, uma vez determinada a curva de serviço do sistema correspondente. Na seção seguinte, mostra-se a aplicação desta equação ao sistema OFDM-TDMA.

Proposição 1. Seja $E\left[K_{r}\right]$ a média do tráfego real de entrada agregado numa escala de tempo $r$, $X$ o tamanho do buffer do usuário e $S(t)$ a sua curva de serviço, a probabilidade de transbordo do buffer do usuário em questão é dada por:

$$
P_{\text {trans }}=\min _{\forall r} \frac{E\left[K_{r}\right]}{X+S(r)}
$$

Proposição 2. Assumindo que o processo envelope do tráfego acumulado é descrito pelo processo envelope do modelo fBm (fractional Brownian motion) [15] e considerando que $\lambda, \sigma e$ H sejam a média, o desvio padrão e o parâmetro de Hurst do tráfego de entrada do usuário, respectivamente, a probabilidade de transbordo do buffer é dada por:

$$
P_{\text {transb }}=\min _{\forall r} \frac{\lambda r+k \sigma r^{H}}{X+S(r)}
$$

Prova. Considere um sistema de fila única com um servidor com taxa de atendimento $s(t)$ e um buffer de comprimento $X$. A quantidade de tráfego que pode ser transmitida em um intervalo de tempo $[0, t)$, também chamada de curva de serviço, é, então, determinada por:

$$
S(t)=\sum_{\tau=0}^{t-1} s(\tau)
$$


Seja $A(t)$ a quantidade total de trabalho (pacotes) acumulado que chega ao buffer no intervalo $[0, t)$, a fila de pacotes formada, ou a quantidade total de tráfego armazenado no buffer no intervalo $[0, t)$, será dada por:

$$
Q(t)=A(t)-S(t)
$$

Agora seja $W$ uma variável aleatória não negativa e $w$ um possível valor de $W$. A inequação de Markov estabelece que [20]:

$$
P\{W \geq w\} \leq \frac{E[W]}{w}
$$

Sendo $K_{r}$ o processo estocástico que define a série de tráfego agregada na escala de tempo $r$, pode-se escrever:

$$
P\left\{K_{r} \geq X+S(r)\right\} \leq \frac{E\left[K_{r}\right]}{X+S(r)}
$$

Observe que o processo $K_{r}$ define a função $A(t)$.

Foram realizadas simulações em um cenário simples de um servidor com um buffer de tamanho finito tendo como entrada séries reais de tráfego de rede. Ao calcularmos a probabilidade de transbordo do buffer para 20 séries de tráfego analisadas, constatamos que, em $95 \%$ dos casos, $P\left\{K_{r} \geq X+S(r)\right\}$ é aproximadamente igual a $\frac{E\left[K_{r}\right]}{X+S(r)}$ na escala $r$ que gera o menor valor de $\frac{E\left[K_{r}\right]}{X+S(r)}$ com erro inferior a $10 \%$. Portanto, assumimos que a seguinte aproximação é válida:

$$
P\left\{K_{r}-S(r) \geq X\right\} \approx \min _{\forall r} \frac{E\left[K_{r}\right]}{X+S(r)}
$$

Dessa forma, a probabilidade de transbordo pode ser escrita como:

$$
P_{\text {trans }}=P\{Q>X\}=\min _{\forall r} \frac{E\left[K_{r}\right]}{X+S(r)}
$$

A esperança matemática do tráfego agregado $\left(E\left[K_{r}\right]\right)$ pode ser obtida por meio de um processo envelope. Um processo envelope nada mais é que um limitante superior para o processo real de tráfego de pacotes acumulado e, portanto, seria uma estimativa de $A(t)$.

Partindo do modelo fBm (fractional Brownian motion), uma aproximação para o processo envelope de fluxos de tráfego real pode ser obtida pela seguinte equação [15] [16]:

$$
\hat{A}(t)=\lambda t+k \sigma t^{H}
$$

onde $\lambda$ e $\sigma$ são a média e o desvio padrão do tráfego de entrada, respectivamente; $k$ é uma constante relacionada à probabilidade de violação do processo envelope $(\epsilon)$, calculada por $k=$ $\sqrt{-2 \ln \epsilon}$, e $H$ é o parâmetro de Hurst, que mede a autossimilaridade do processo de tráfego de entrada. Em outras palavras, a equação 4.6 requer o cálculo do processo envelope da série de tráfego, que pode ser feito através de estimativas da média, do desvio padrão e do parâmetro de Hurst do tráfego. 
Dessa forma, $E\left[K_{r}\right] \approx \hat{A(r)}$, e a probabilidade de transbordo pode ser encontrada por:

$$
P_{\text {transb }}=\min _{\forall r} \frac{\lambda r+k \sigma r^{H}}{X+S(r)}
$$

\subsection{Curva de Serviço Aplicada ao Cálculo da Probabilidade de Transbordo em Sistemas OFDM-TDMA}

Deseja-se adequar a equação 4.8 para determinar a probabilidade de transbordo do buffer de um usuário no mesmo sistema OFDM-TDMA definido na seção 3 Para isso, é necessário determinar a curva de serviço do usuário nesse sistema.

Proposição 3. A curva de serviço de um usuário de um sistema OFDM-TDMA com escalonamento round-robin onde cada usuário é servido pelo mesmo intervalo de tempo $T$ é dada por:

$$
S_{n}(t)=c T P+c T \min \left\{\frac{\max [t-P N T-(n-1) T ; 0]}{T} ; 1\right\}
$$

Prova. Assumindo que o sistema OFDM-TDMA descrito possua 4 usuários, a curva de serviço do usuário 1 (o primeiro a ser atendido, em $t=0$ ) pode ser visualizada na Figura 1.

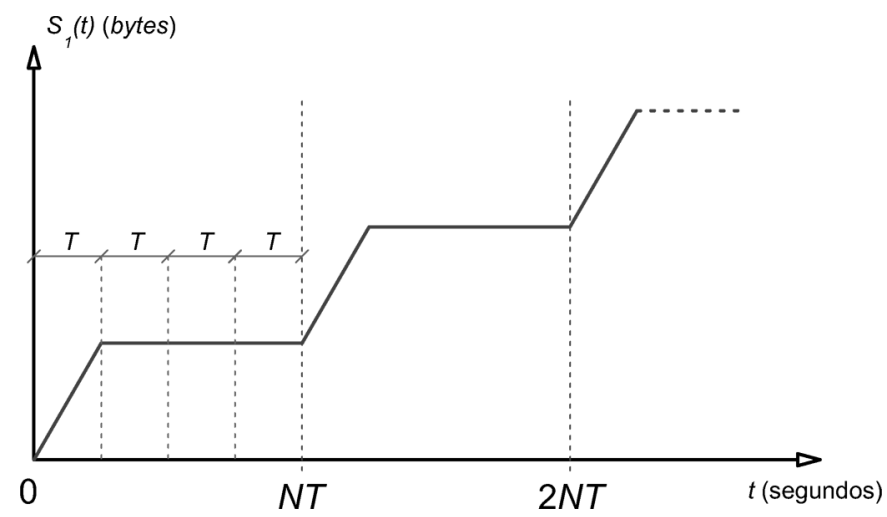

Figura 1: Curva de serviço do usuário 1.

A ilustração mostra dois ciclos do escalonamento round-robin. Pode-se observar claramente que, nos primeiros $T$ segundos de cada ciclo, o usuário 1 é atendido, enquanto, nos $3 T$ segundos restantes, ele aguarda.

Assume-se que o coeficiente angular da reta que vai de $t=0$ até $t=T$ seja dado por $c$, a média da taxa de atendimento no servidor do sistema OFDM-TDMA.

$$
c=\sum_{r=0}^{R} r\left[\mathbf{R}_{n}\right]_{r+1}
$$


Dessa forma, a curva de serviço do usuário 1 pode ser calculada como a soma do tráfego transmitido nos ciclos completos e do tráfego já transmitido no ciclo atual.

$$
S_{1}(t)=S_{1 C}(t)+S_{1 A}(t)
$$

O número de ciclos completos é dado por $P=\left\lfloor\frac{t}{N T}\right\rfloor$. Assim, o tráfego transmitido nos ciclos já completados é calculado por:

$$
S_{1 C}(t)=c T P
$$

O tráfego transmitido no ciclo atual, por sua vez, é calculado por:

$$
S_{1 A}(t)=c T \min \left(\frac{t-P N T}{T} ; 1\right)
$$

Logo, a curva de serviço do usuário 1 é dada por:

$$
S_{1}(t)=c T P+c T \min \left(\frac{t-P N T}{T} ; 1\right)
$$

O que pode ser generalizado para qualquer usuário como:

$$
S_{n}(t)=c T P+c T \min \left\{\frac{\max [t-P N T-(n-1) T ; 0]}{T} ; 1\right\}
$$

A equação 4.14 pode ser calculada de forma recursiva, ou seja, armazenando o valor de uma janela de tempo anterior, consegue-se fazer uma estimativa da curva de serviço atual.

A probabilidade de transbordo do buffer de um usuário $n$ no sistema OFDM-TDMA pode ser aproximada pelas equações 4.15 e 4.16 , com base no processo envelope real e no processo envelope do modelo fBm, respectivamente.

$$
\begin{aligned}
P_{\text {trans }_{n}} & =\min _{\forall r} \frac{E\left[K_{r}\right]}{X+S_{n}(r)} \\
P_{\text {trans }_{n}} & =\min _{\forall r} \frac{\lambda r+k \sigma r^{H}}{X+S_{n}(r)}
\end{aligned}
$$

\subsection{Simulações e Resultados}

Nos experimentos realizados, foi analisado o desempenho da fila de um usuário no sistema OFDM-TDMA com 5 conexões ativas. O tráfego dos usuários foi modelado a partir das seguintes séries: voip-call-1, série recentemente coletada no laboratório da UFG, e as séries de tráfego IP de dados dec-pkt-1, dec-pkt-1, dec-pkt-2, lbl-pkt-4 e lbl-pkt-5 [21].

Cada amostra das séries registra a quantidade de bytes que formam o pacote transmitido. Neste experimento, considerou-se que as amostras foram coletadas a cada milissegundo. Os primeiros 1500 valores de cada uma das séries de tráfego consideradas são mostrados nas Figuras 2 e 3. 


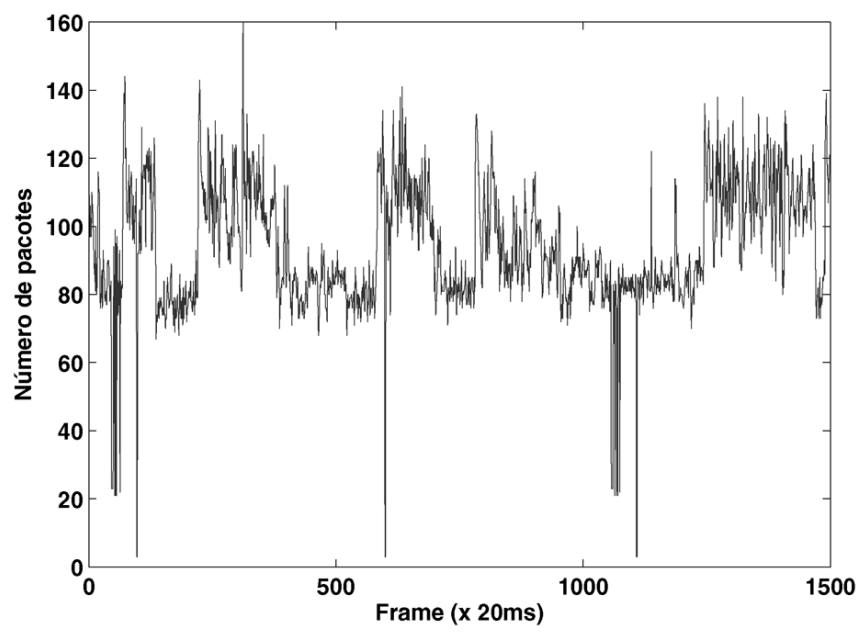

Figura 2: Número de pacotes que chegam em cada frame considerando a série voip-call-1.

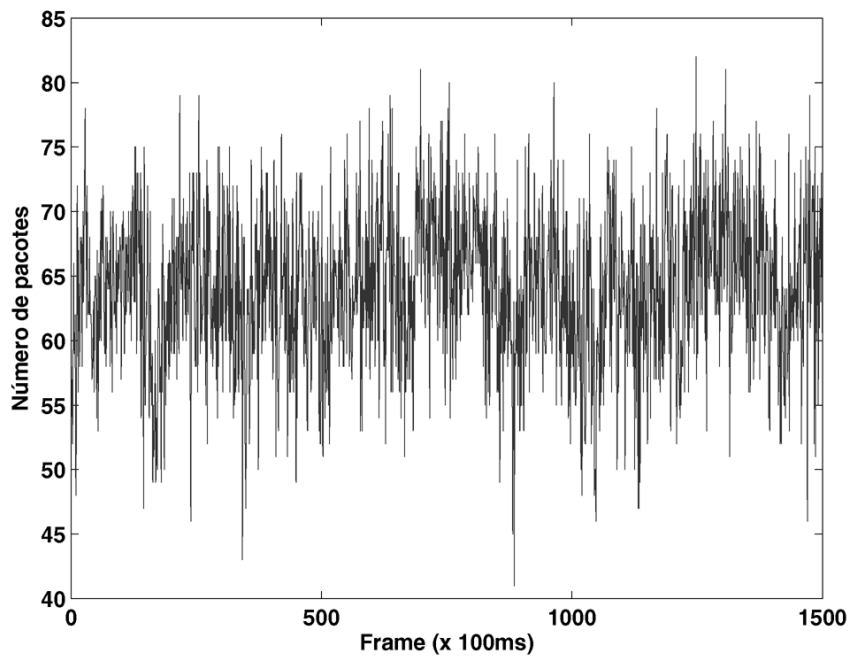

Figura 3: Número de pacotes que chegam em cada frame considerando a série dec-pkt-1.

Seja um cenário para o sistema OFDM-TDMA com os seguintes parâmetros: $M=512, N=5$, $B=20,0 \mathrm{MHz}, P_{b e r}=10^{-6}, C=6, T=20 \mathrm{~ms}$ e $L=59$ bytes, sendo que um usuário é servido por apenas um frame por ciclo do escalonamento round-robin e fixando a SNR em $14 \mathrm{~dB}$. A Figura 4 compara as curvas de serviço obtidas através da equação 4.14 e através de simulação. A partir do modelo considerado para o canal OFDM com base no desvanecimento rápido de Rayleigh (assumindo-se os mesmos parâmetros da Figura 4, foram obtidas as funções massa de probabilidade da taxa de transmissão total do canal (equação 2.8) mostradas nas Figuras 5 para um intervalo de valores de SNR. Como esperado, o aumento da relação sinal-ruído ocasiona uma melhoria na qualidade do canal, dado que a taxa média de transmissão é incrementada. 


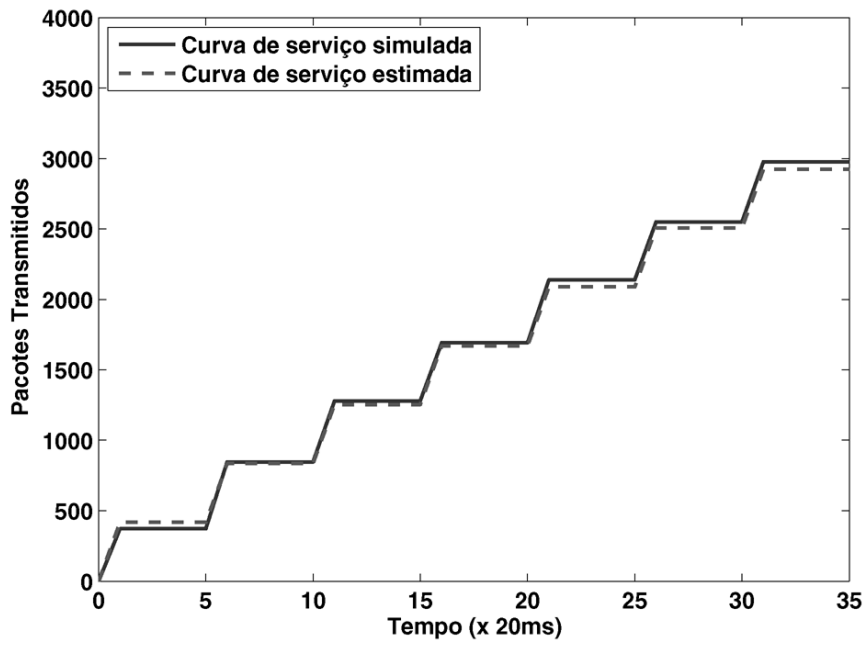

Figura 4: Curva de serviço do usuário 1 no cenário considerado do sistema OFDM-TDMA.

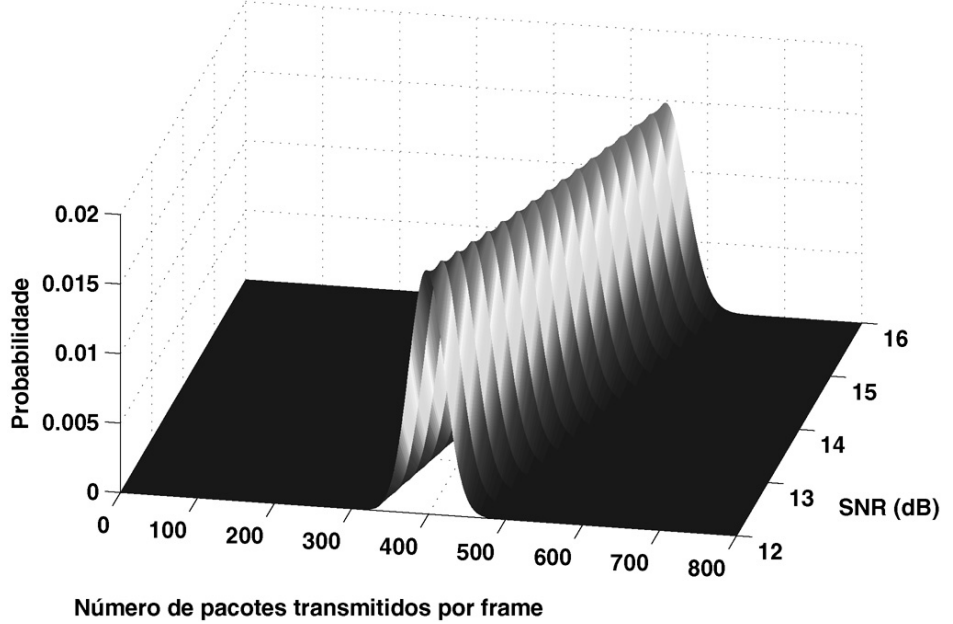

Figura 5: Função massa de probabilidade da taxa de transmissão total para diferentes valores de SNR no Cenário 1 .

Com base nas equações 4.15 e 4.16, a Figura 6 apresenta a relação da probabilidade de transbordo do buffer do usuário com o aumento do tamanho deste, considerando as mesmas circunstâncias assumidas na Figura 5, onde o tráfego dos usuários é modelado a partir de chamadas VoIP. A Figura 6 ainda mostra estimativas de probabilidade de transbordo obtidas com a equação 3.10 e com o método MSQ (MultiScale Queueing). O MSQ, bastante difundido em outros trabalhos, parte da análise multiescala do tráfego de entrada e considera que este seja descrito pelo modelo MWM (Multifractal Wavelet Model) [22]. 


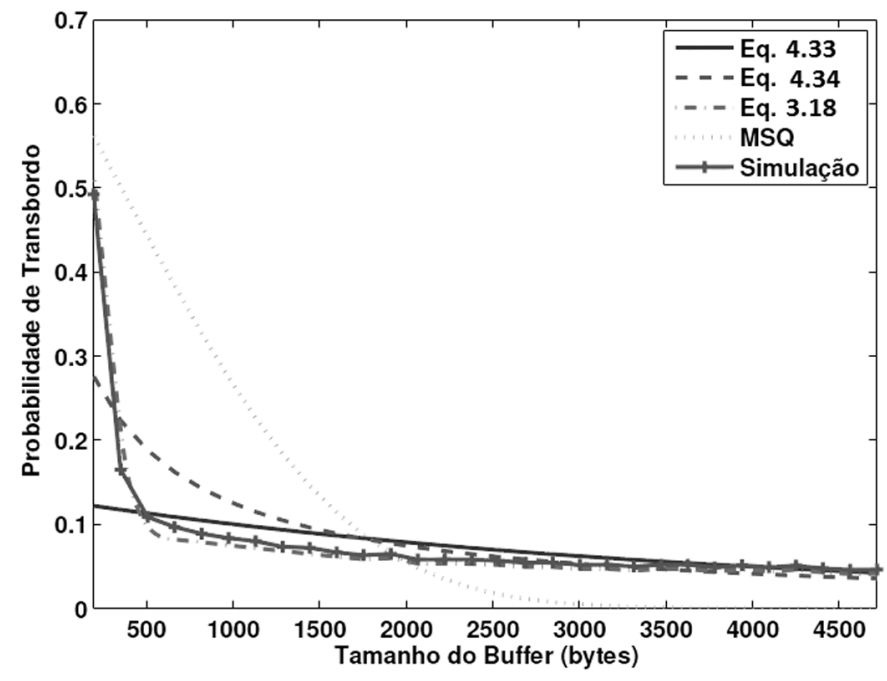

Figura 6: Probabilidade de transbordo do buffer do usuário no cenário considerado do sistema OFDM-TDMA.

Observa-se que a estimativa obtida com a equação 3.10 se aproxima bastante da simulação, porém o custo computacional para encontrá-la é significativamente elevado. Por outro lado, os resultados das equações 4.15 e 4.16 se aproximam consideravelmente da probabilidade de transbordo real mantendo uma relativa simplicidade na obtenção das estimativas e possibilitando sua utilização para mensuração em tempo real.

Conforme mostram a Tabela 1 e as Figuras 7 a 11, diferentes cenários são considerados para validar a eficiência das equações 4.15 e 4.16. Em cada cenário o perfil de tráfego do usuário é definido a partir de uma série distinta, como discriminado na tabela. As séries levadas em conta foram criadas a partir da coleta de amostras reais de tráfego de redes TCP/IP [21].

Tabela 1: Cenários do sistema OFDM-TDMA considerados.

\begin{tabular}{|c|c|c|c|c|c|}
\hline Cenário & $\mathbf{1}$ & $\mathbf{2}$ & $\mathbf{3}$ & $\mathbf{4}$ & $\mathbf{5}$ \\
\hline Figura & 7 & 8 & 9 & 10 & 11 \\
\hline Série & dec- $p k t-1$ & dec- $p k t-2$ & $l b l-p k t-4$ & $l b l-p k t-5$ & $l b l-p k t-5$ \\
\hline$T(\mathrm{~ms})$ & 512 & 512 & 100 & 100 & 512 \\
\hline$N$ & 5 & 5 & 5 & 7 & 8 \\
\hline$M$ & 512 & 512 & 256 & 256 & 256 \\
\hline$B(\mathrm{MHz})$ & 8 & 15 & 2,5 & 2,5 & 2,5 \\
\hline$P$ & $10^{-6}$ & $10^{-6}$ & $10^{-6}$ & $10^{-6}$ & $10^{-6}$ \\
\hline$C$ (bits/sím) & 5 & 5 & 5 & 5 & 5 \\
\hline
\end{tabular}




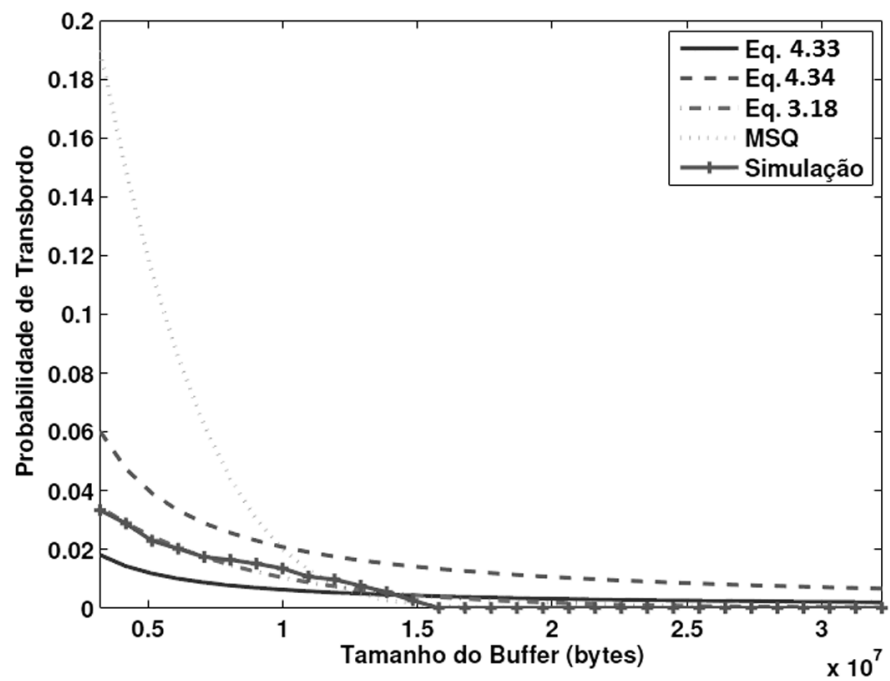

Figura 7: Probabilidade de transbordo do buffer no Cenário 1.

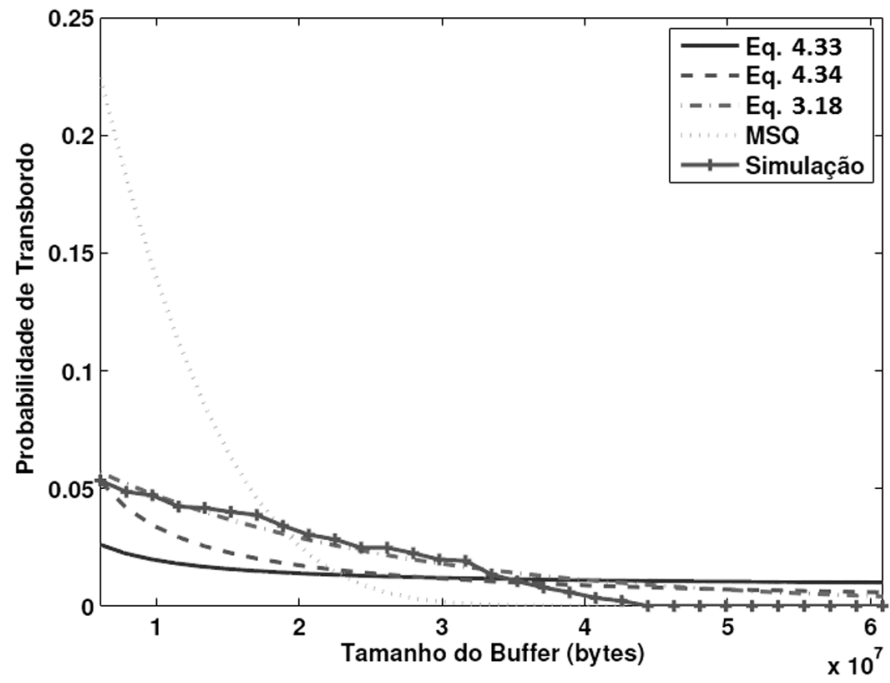

Figura 8: Probabilidade de transbordo do buffer no Cenário 2.

Os experimentos realizados para cada cenário demonstram coerência nos resultados obtidos para a probabilidade de transbordo do buffer. As estimativas calculadas se apresentaram muito próximas dos valores reais obtidos via simulação. Os resultados, portanto, validam a eficiência das equações 4.15 e 4.16 tornando-as opções facilmente aplicáveis e rápidas para avaliar a qualidade de serviço em sistemas OFDM-TDMA. Além disso, para avaliar o resultado da equação proposta para estimação de probabilidade de transbordo quando o número de usuários muda, utilizamos 7 e 8 usuários nos cenários 4 e 5 da Tabela 1, respectivamente. Neste caso, observamos 


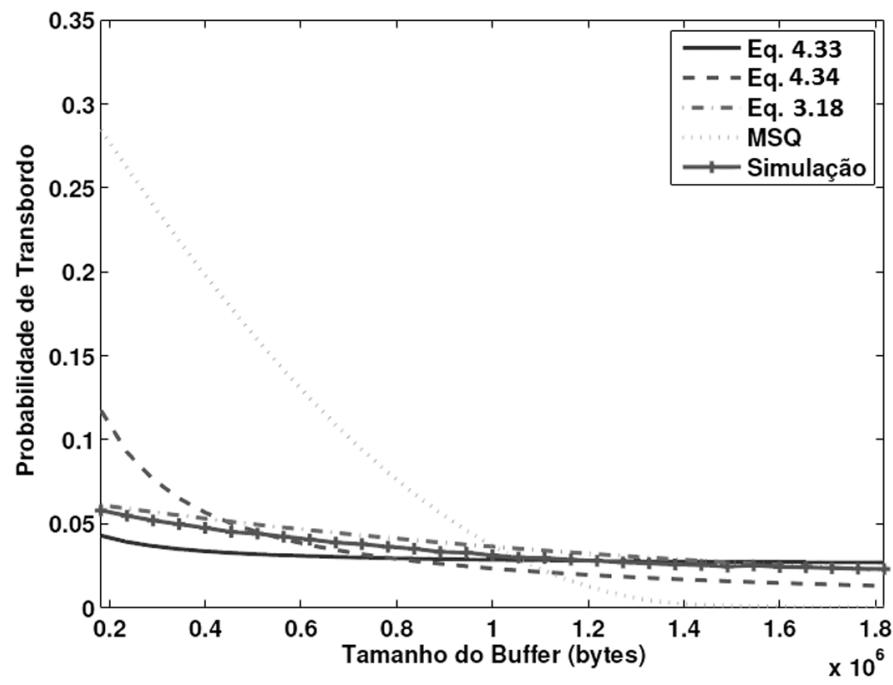

Figura 9: Probabilidade de transbordo do buffer no Cenário 3.

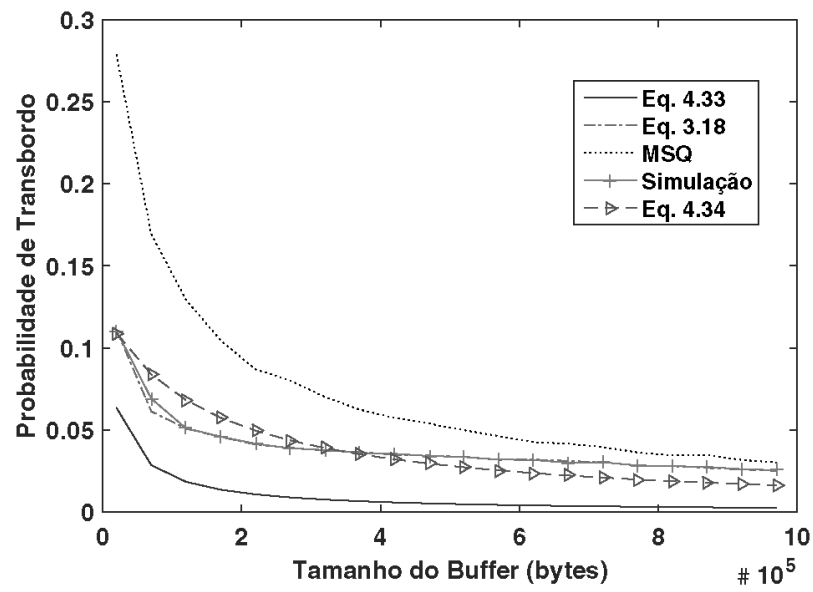

Figura 10: Probabilidade de transbordo do buffer no Cenário 4.

que a equação proposta 4.16 forneceu valores para probabilidade de transbordo próximos dos valores reais. Inclusive, para os valores de buffer considerados, é a curva mais próxima da curva real de probabilidade de transbordo.

A equação 4.15 faz uso do processo envelope real, obtido a partir da série do tráfego considerado, e, por isso, se aproxima mais da probabilidade de transbordo real. No entanto, a estimativa do processo envelope real em inúmeras escalas exigido por esta equação, pode afetar o tempo demandado para cálculo da probabilidade de transbordo. Ao se considerar o modelo fBm, a equação 4.16 utiliza uma estimativa relevante do processo envelope e simplifica o cálculo significativamente mantendo resultados satisfatórios. 


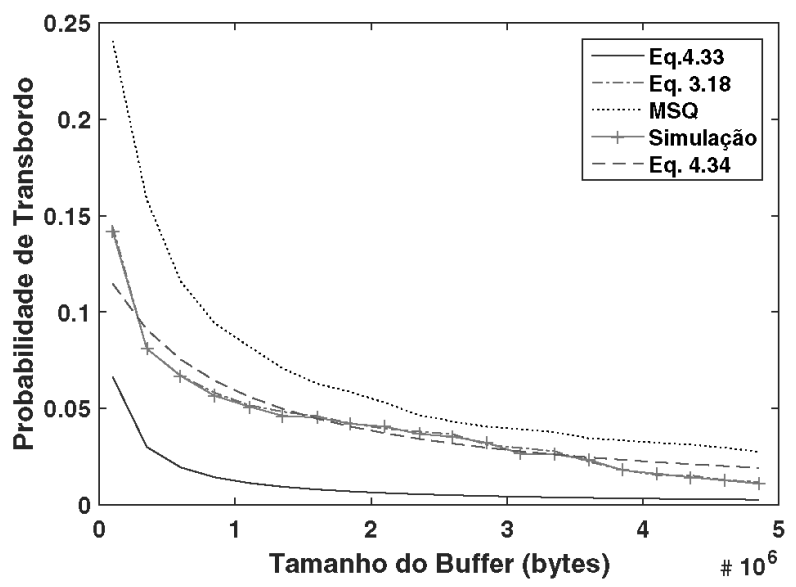

Figura 11: Probabilidade de transbordo do buffer no Cenário 5.

As estimativas obtidas com a equação 3.10 se mostraram ligeiramente mais próximas dos valores reais (simulações). Mas, apesar de o modelo baseado em Cadeias de Markov possibilitar a estimação de alguns parâmetros de QoS além da probabilidade de transbordo, sua aplicação é limitada devido à complexidade computacional envolvida. A equação proposta 4.16 permite obter uma estimativa da probabilidade de perda utilizando operações de baixo custo computacional como: somas, uma divisão e uma operação de mínimo. Já o algoritmo baseado em Cadeia de Markov (3.18), exige a resolução de um sistema de equações, entre outros cálculos, o que implica em uma complexidade computacional maior do que a equação proposta, o que pode ser quantificado em termos de tempo de processamento. Para os cenários de 1 a 5, utilizando um computador equipado com processador Intel®Core ${ }^{\mathrm{TM}} \mathrm{i} 7$ de terceira geração e $6 \mathrm{~GB}$ de RAM, a equação proposta demanda em média cerca de 2 segundos para ser calculada, ao passo que o algoritmo baseado em cadeia de Markov demanda em média 30 minutos de processamento. Assim, a probabilidade de transbordo é uma medida que expressa bem a qualidade de serviço, o que torna as equações 4.15 e, principalmente, 4.16 muito úteis em aplicações que exigem rápido processamento.

\section{CONCLUSÕES}

A modulação OFDM é uma técnica de multiplexação amplamente difundida nos sistemas de comunicações sem fio atuais. É caracterizada por sua alta resistência contra interferências intersimbólicas e de multipercurso, além da elevada eficiência espectral.

Por meio do uso de Cadeias de Markov, foi possível descrever o comportamento da fila do usuário em estado estacionário, conhecendo a probabilidade da fila se encontrar em cada estado possível. A partir dessas probabilidades, foram definidos alguns indicadores úteis na análise do desempenho dos sistemas em questão: o número médio de pacotes na fila formada para transmissão, o atraso médio no envio de um pacote e a probabilidade de que haja transbordo no buffer do usuário. 
No entanto, a construção da matriz de transição da Cadeia de Markov e sua posterior solução no estado estacionário demandam muitos recursos computacionais, dada a complexidade do cálculo matricial envolvido. Uma outra abordagem para análise de desempenho do mesmo sistema foi desenvolvida. Esta consiste na estimação da probabilidade de transbordo do buffer do usuário do sistema OFDM-TDMA através de uma equação que leva em consideração o processo envelope fractal do tráfego de entrada e sobre a curva de serviço do sistema. Dessa maneira, foi possível embutir ao modelo formas precisas de descrever o processo de tráfego do usuário e o canal de transmissão do sistema.

Como foi visto, a equação obtida provê resultados bastante satisfatórios. As estimativas de probabilidade de transbordo encontradas, comparadas com resultados de outros modelos, se aproximaram consideravelmente das probabilidades de transbordo obtidas com simulações, o que corrobora para a eficiência da equação apresentada. Observa-se que o modelo baseado em Cadeias de Markov fornece resultados mais próximos dos reais, proporcionando uma análise de desempenho do sistema bastante eficaz, porém, a custo muito elevado. A equação 4.16, no entanto, fornece resultados com prejuízo pequeno de precisão mas a muito baixo custo computacional, possibilitando até seu uso para análise de desempenho do sistema em tempo real. Além disso, tendo a relação entre a taxa de perda e o número de usuários, pode-se empregar a equação proposta em um sistema de controle de admissão de usuários, o que será avaliado em trabalhos futuros.

\begin{abstract}
This paper presents two approaches for estimating buffer overflow probability in OFDM-TDMA networks. The first approach is based on Queuing Theory and Markov Chains and is used to evaluate the performance of the transmission link in OFDM-TDMA systems. The second approach is based on Network Service Curve and Envelope Processes of the traffic flows. More specifically, it is proposed an equation to estimate the probability of buffer overflow in OFDM-TDMA systems. To this end, an equation for the Service Curve of the considered system, is also proposed. The results show that the estimates are very close to those obtained by simulations and that the computational complexity to obtain them are significantly reduced due to the absence of matrix computation.
\end{abstract}

Keywords: OFDM-TDMA networks, Overflow Probability, Markov Chains, Queue Theory, Envelope Processes, Service Curve.

\title{
REFERÊNCIAS
}

[1] R. Prasad. Ofdm for Wireless Communications Systems. Artech House, 2004. (Artech House universal personal communications series).

[2] IEEE. Wireless LAN Medium Access Control (MAC) and Physical Layer (PHY) Specifications. New York, NY (2012).

[3] IEEE. IEEE Standard for Local and Metropolitan Area Networks - Part 16: Air Interface for Fixed Broadband Wireless Access Systems. New York, NY, USA (2004).

[4] 3GPP. Evolved Universal Terrestrial Radio Access (E-UTRA) and Evolved Universal Terrestrial Radio Access Network (E-UTRAN); Overall description. Valbonne, FR (2013).

[5] V. Tarokh. New Directions in Wireless Communications Research. Springer (2009). 
[6] J.D.C. Little. A Proof of the Queuing Formula: $L=\lambda W$. Operations Research, 9(3) (1961), 383-387.

[7] D. Niyato \& E. Hossain. Queueing analysis of ofdm/tdma systems. IEEE Global Telecommunications Conference, 6(5), 3712-3716. December (2005).

[8] F.G.C. Rocha, C.B. Santos \& F.H.T. Vieira. Traffic Modeling in PLC Networks using a Markov Fluid Model with Autocorrelation Function Fitting. TEMA - Trends in Applied and Computational Mathematics, 12(3) (2011), 233-243.

[9] J.W. Bosman, R.D. Van der Mei \& R. Nunez-Queija. A Fluid Model Analysis of Streaming Media in the Presence of Time-varying Bandwidth. 24th International Teletraffic Congres, (2012), 1-8.

[10] Jui-Chi Chen \& Wen-Shyen E. Chen. Call blocking probability and bandwidth utilization of OFDM subcarrier allocation in next-generation wireless networks. IEEE Communications Letters, 10(2) (2006), 82-84. February.

[11] G. Wunder \& Chan Zhou. Queueing analysis for the OFDMA downlink: Throughput regions, delay and exponential backlog bounds. IEEE Transactions on Wireless Communications, 8(2) (2009), 871-881. February.

[12] A. El Bouchti, S. El Kafhali \& A. Haqiq. Queueing performance analysis of CAC scheme in OFDMA based WiMAX system. 3rd International Conference on Next Generation Networks and Services (NGNS), (2011), 62-67. December.

[13] V. Paxson \& S. Floyd. Wide area traffic: the failure of Poisson modeling. IEEE/ACM Transactions on Networking, 3(3) (1995), 226-244. June.

[14] F.H.T. Vieira \& L.L. Lee. Adaptive wavelet-based multifractal model applied to the effective bandwidth estimation of network traffic flows. IET Communications, 3 (2009), 906-919.

[15] G. Mayor \& J. Silvester. Time Scale Analysis of an ATM Queueing System With Long-Range Dependent Traffic. Sixteenth Annual Joint Conference of the IEEE Computer and Communications Societies, (1997), 205-212.

[16] J.A. Santos Junior \& F.H.T. Vieira. Algoritmo de Policiamento de Tráfego para Redes OFDM-TDMA WiMAX Baseado em Modelagem Multifractal e Cálculo de Rede. Escola de Engenharia Elétrica e de Computação - Universidade Federal de Goiás. Goiânia, GO, BR. (2011).

[17] S. Coleri, M. Ergen, A. Puri \& A. Bahai. Channel estimation techniques based on pilot arrangement in OFDM systems. IEEE Transactions on Broadcasting, 48(3) (2002), 223-229. September.

[18] Xiaoxin Qiu \& K. Chawla. On the performance of adaptive modulation in cellular systems. IEEE Transactions on Communications, 47(6) (1999), 884-895. June.

[19] J. Leeuwaarden, M. Squillante \& E. Winands. Quasi-Birth-And-Death Processes, Lattice Path Counting, and Hypergeometric Functions. Journal of Applied Probability, 46(2) (2009), 507-520. June.

[20] A. Papoulis \& S.U. Pillai. Probability, random variables, and stochastic processes. McGraw-Hill, (2002). (McGraw-Hill electrical and electronic engineering series).

[21] WRL. The Internet Traffic Archive: Hour-long Traces of Wide-Area Traffic from Digital Equipment Corporation, by Western Research Lab. (1995). Available on: http://ita.ee.lbl.gov/html/contrib/DECPKT.html.

[22] V.J. Ribeiro, R.H. Riedi, M.S. Crouse \& R.G. Baraniuk. Multiscale Queuing Analysis of Long-RangeDependent Network Traffic. Nineteenth Annual Joint Conference of the IEEE Computer and Communications' Societies, (2000), 1026-1035.

[23] ITA. Hour-long Traces of Wide-Area Traffic. The Internet Traffic Archive. Available on: http://ita.ee.lbl.gov/html/traces.html. Last visit: Aug. (2013). 